\title{
Immobilization-assisted abdominal deep inspiration breath-hold in post-mastectomy radiotherapy of left-sided breast cancer with internal mammary chain coverage
}

\author{
Meiqin Chen ${ }^{1 \#}$, Shoumei Zang ${ }^{2 \#}$, Hao $\mathrm{Yu}^{2}$, Lihua Ning ${ }^{2}$, Huijie Huang ${ }^{3}$, Luyi Bu ${ }^{2}, \mathrm{Jia} \mathrm{Ge}^{2}, \mathrm{Mengyou} \mathrm{Xu}^{2}$, \\ Qiuying Tang ${ }^{2}$, Feng Zhao ${ }^{2}$, Guorong Yao ${ }^{2}$, Senxiang Yan ${ }^{2}$ \\ ${ }^{1}$ Department of Radiation Oncology, the First Affiliated Hospital, College of Medicine, Zhejiang University, Hangzhou and Department of \\ Radiation Oncology, Affiliated Jinhua Hospital, College of Medicine, Zhejiang University, Jinhua, China; ${ }^{2}$ Department of Radiation Oncology, \\ the First Affiliated Hospital, College of Medicine, Zhejiang University, Hangzhou, China; ${ }^{3}$ Department of Radiation Oncology, YiLi Friendship \\ Hospital, Yili, China
}

"These authors contributed equally to this work.

Correspondence to: Senxiang Yan. Department of Radiation Oncology, the First Affiliated Hospital, College of Medicine, Zhejiang University, 79 Qingchun Road, Hangzhou 310003, China. Email: yansenxiang@zju.edu.cn.

Background: Whether to prophylactically irradiate the ipsilateral internal mammary chain (IMC) in postmastectomy radiotherapy (PMRT) remains controversial because of equivocal clinical benefits against the added toxicities. Our previous study revealed that the cardiac dose was decreased during left-sided breast radiotherapy with abdominal deep inspiration breath-hold (aDIBH) as compared with free-breathing (FB) and thoracic deep inspiration breath-hold (tDIBH). Here we present the dosimetric advantage of aDIBH for patients undergoing PMRT with IMC coverage.

Methods: We prospectively analyzed 19 patients with left-sided breast cancer who underwent PMRT. Patients underwent computed tomography (CT) simulation under both free-breathing (FB) and aDIBH. The heart, left anterior descending coronary artery (LAD), lungs, and the contralateral breast was defined as organs at risk (OARs). Three-dimensional conformal radiation therapy (3D-CRT), inverse planning intensity-modulated radiation therapy (IMRT), and volumetric modulated arc therapy (VMAT) were used to calculate the doses received by both the planning target volume (PTV) and OARs, which were compared using the Wilcoxon signed-rank test.

Results: Compared with FB, the $\mathrm{D}_{\text {mean }}$ of the heart and LAD were respectively reduced by 3.5 Gy $(\mathrm{P}<0.003)$ and $8.9 \mathrm{~Gy}(\mathrm{P}<0.001)$ in 3D-CRT, 2.6 Gy $(\mathrm{P}<0.001)$, and $7.8 \mathrm{~Gy}(\mathrm{P}=0.001)$ in IMRT, $1.5 \mathrm{~Gy}(\mathrm{P}<0.001)$ and $4.5 \mathrm{~Gy}(\mathrm{P}=0.001)$ in VMAT plans under aDIBH. Among all these plans, the $\mathrm{D}_{\text {mean }}$ of the heart was lowest

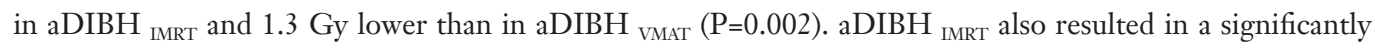
reduced dose to the ipsilateral lung than plans under $\mathrm{FB}(\mathrm{P}<0.05)$. $\mathrm{D}_{\text {mean }}$ and V5 to the contralateral lung and breast were higher in VMAT plans $(\mathrm{P}<0.05)$.

Conclusions: Using an immobilization-assisted aDIBH technique, radiation doses to the heart can be kept at reasonably low levels even if IMC is included in the clinical target volume (CTV). Among 3D-CRT, IMRT, and VMAT plans, IMRT plus aDIBH results in the best heart-sparing effect. We recommend that the aDIBH technique be routinely applied in suitable patients if the IMC is irradiated.

Keywords: Breast cancer; abdominal deep inspiration breath-hold (aDIBH); internal mammary chain (IMC); post-mastectomy radiotherapy (PMRT)

Submitted Jul 05, 2020. Accepted for publication Oct 18, 2020.

doi: 10.21037/qims-20-831

View this article at: http://dx.doi.org/10.21037/qims-20-831 


\section{Introduction}

Breast cancer ranks first in female cancer incidence worldwide (1). Adjuvant radiotherapy reduces recurrence and prolonged survival, especially in patients with lymph node involvement $(2,3)$. Post-mastectomy radiotherapy (PMRT) usually encompasses the chest wall and regional lymph nodes, but whether to prophylactically irradiate the ipsilateral internal mammary chain (IMC) remains controversial because of conflicting data about the gains and losses of this treatment strategy (4-6). It is especially true of left-sided breast cancer where the heart is an organ at risk (OAR). Numerous reports have demonstrated increased cardiac morbidity and mortality years after adjuvant radiotherapy (RT) to the left-sided breast (7-11), which negated RT's benefits.

Although the threshold cardiac dose is poorly understood, it is believed that each increased dose unit (Gy) translates into a proportional rise in the likelihood of heart damage and ischemic heart disease $(8,12)$. Unlike those early breast cancer patients undergoing postoperative whole breast irradiation, almost all patients undergoing PMRT with IMC coverage will have been administered chemotherapy or even anti-HER2 therapies, which together can lead to additional toxicities (13). Over the past decades, several measures have been introduced to minimize doses to the heart during PMRT for left-sided breast cancer (5), including technical improvements of the Linac which is a linear accelerator equipment, respiratory gating to reduce the internal target volume (ITV), and deep inspiration breath-hold (DIBH) during RT $(14,15)$. Since the first report in a small cohort of patients in 2001 by Sixel et al. (16), DIBH has been extensively studied in patients undergoing PMRT. Overall, considerable dose reduction of the heart and lungs was observed using DIBH regardless of the RT technique.

Nevertheless, there remain drawbacks to the currently practiced DIBH technique. Thoracic respiration is multi-muscular action that includes the intercostal muscles and the diaphragm. It is two-dimensional, thoracic respiration, if mostly using the intercostal muscles or abdominal respiration if mostly using the diaphragm. Accordingly, DIBH is not unidimensional but has thoracic (tDIBH) and abdominal DIBH (aDIBH) components. Changes in the proportion of these lead to target shifts. Understandably, one study reported significant movement of the lymph node areas due to DIBH, which implies a larger internal target volume
(ITV) is needed to compensate for the movement (17). Our previous study found that by reducing the thoracic proportion as much as possible, aDIBH could further decrease the cardiac dose (18) because the significantly lowered heart position keeps it further away from the clinical target volume (CTV).

The IMC usually runs from the first to the fifth intercostal spaces adjacent to the sternum. During aDIBH, the sternum and the IMC remain almost motionless while the heart moves caudally together with the diaphragm. Given this geometrical advantage of aDIBH, we conducted a comparative dosimetric study of aDIBH and FB to maximally reduce the cardiac doses in the clinical setting of PMRT with IMC coverage.

\section{Methods}

\section{Ethics}

This study was approved by the hospital's Institutional Review Board and complied with the Code of Ethics of the World Medical Association (Declaration of Helsinki) for trials involving humans. Informed consent was given by all patients, who were carefully screened to rule out any contraindications to aDIBH.

\section{Participants and preparations}

From March 2018 to June 2019, 19 left-sided breast cancer patients (median age 52 years, range 31-69 years) with $\geq 4$ axillary lymph nodes metastasis were included in the study. Before CT simulation, all patients were coached by a specialty nurse to familiarize them with the procedure of aDIBH. They were instructed to keep practicing for at least 1 week at home with video guidance. Key points of the practice were to use the diaphragm to displace the abdominal contents downwards during deep inspiration, keep the chest wall relatively motionless, and hold the breath for at least $10-15 \mathrm{~s}$ at the end of each maximal inhalation. This procedure was repeated 5-7 times, corresponding to the beam-on times during each treatment session.

\section{CT simulation}

The patients were placed on a dedicated breast board with a specially designed thermoplastic mesh (Orfit Industries NV, Wijnegem, Belgium), which served as the immobilization 
Table 1 Planning objectives for IMRT and VMAT optimization

\begin{tabular}{lll}
\hline Optimization & Structure & Planning aim \\
\hline Highest priority & PTV coverage & At least $95 \%$ of PTV covered by 95\% of PD (47.5 Gy) \\
Second priority & Heart dose & Mean dose $\leq 4$ Gy \\
& V8 Gy $<10 \%$ \\
& V20 Gy $<5 \%$ \\
Lesser priority & Left lung & V4 Gy $<55 \%$ and V16 Gy $<25 \%$ \\
& Contralateral lung & V4 Gy $<25 \%$ \\
& Contralateral Breast & V4 Gy $<15 \%$ \\
& Spinal cord & $D_{\max }<45$ Gy \\
\hline
\end{tabular}

PTV, planning target volume; PD, prescribed dose.

device for both setup reproducibility and suppression of thoracic movement. Part of the mesh covering the anterior abdominal wall was hollowed out to allow the abdomen's inflation during aDIBH and facilitation of a Realtime Positioning Management (RPM, Varian Medical System, Palo Alto, CA, USA) system. A tissue equivalent compensator (bolus) of $5 \mathrm{~mm}$ thickness was put on the left chest wall beneath the mesh. All patients underwent plain CT simulation with a $3-\mathrm{mm}$ slice thickness. CT image acquisition under $\mathrm{FB}$ was done first and once, and then two scans under aDIBH for a consistency check. The procedure of CT simulation took about $10 \mathrm{~s}$. Additionally, the patient's head was turned to the right and fixed with a smaller mesh for supraclavicular irradiation (See Figure S1 and Video 1).

\section{Contouring and planning}

Contouring of both the CTV and OARs [i.e., heart, left anterior descending coronary artery (LAD), lungs, and contralateral breast] was done by a senior radiation oncologist specializing in breast cancer radiotherapy, per guidelines recommended by Radiation Therapy Oncology Group (RTOG) Breast Contouring Atlas (19). The CTV included the left chest wall, supra- and infraclavicular regions, and the IMC from the first to the third intercostal spaces. A $5 \mathrm{~mm}$ expansion was added to CTV to form the planning target volume (PTV). The heart was defined as the volume from the lower part of the left pulmonary artery to the apex. The LAD was contoured with a diameter of $5 \mathrm{~mm}$. The left main coronary artery (LMCA) was also contoured. The ipsilateral lung was contoured to exclude the major airways. The longitudinal distance from the sternal notch to the aortic valve (LDNV) in the $\mathrm{Z}$-axis was calculated and compared under both $\mathrm{FB}$ and aDIBH during CT simulation. An Eclipse treatment planning system (Version 11, Varian Medical System, Palo Alto, CA, USA) was applied for dose calculations using the same constraints. The prescribed dose was 5,000 cGy in 25 fractions, requiring $95 \%$ of the PTV receiving at least $95 \%$ of the prescribed dosage. Six plans were generated for each patient, namely FB Three-dimensional conformal radiation therapy (3D-CRT), FB inverse planning intensitymodulated radiation therapy (IMRT), FB volumetric modulated arc therapy (VMAT), aDIBH ${ }_{3 \mathrm{D}-\mathrm{CRT}}$, aDIBH

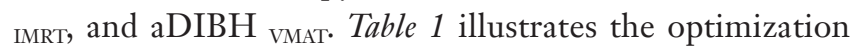
objectives of IMRT and VAMT plans.

The following parameters derived from the dose-volume histogram (DVH) were recorded for statistical analysis: the mean dose $\left(\mathrm{D}_{\text {mean }}\right)$ of PTV, the maximum dose of the $2 \%$ volume (D2\%), the minimum dose of the $98 \%$ volume (D98\%). Homogeneity Index (HI) was calculated with $\mathrm{HI}=(\mathrm{D} 2 \%-98 \%) / 50$. As for OARs, the volumes receiving 5 Gy (V5), 20 Gy (V20) and 30 Gy (V30) were recorded and compared between FB and aDIBH, as well as the mean doses.

\section{Results}

\section{Geometric comparison of $F B$ and aDIBH}

As shown in Figure 1, the relationship between the IMCinclusive PTV and OARs was demonstrated under both FB and aDIBH. With aDIBH, the heart and LAD moved downwards and further away from the PTV. Using the seventh thoracic vertebra as an internal reference, the 

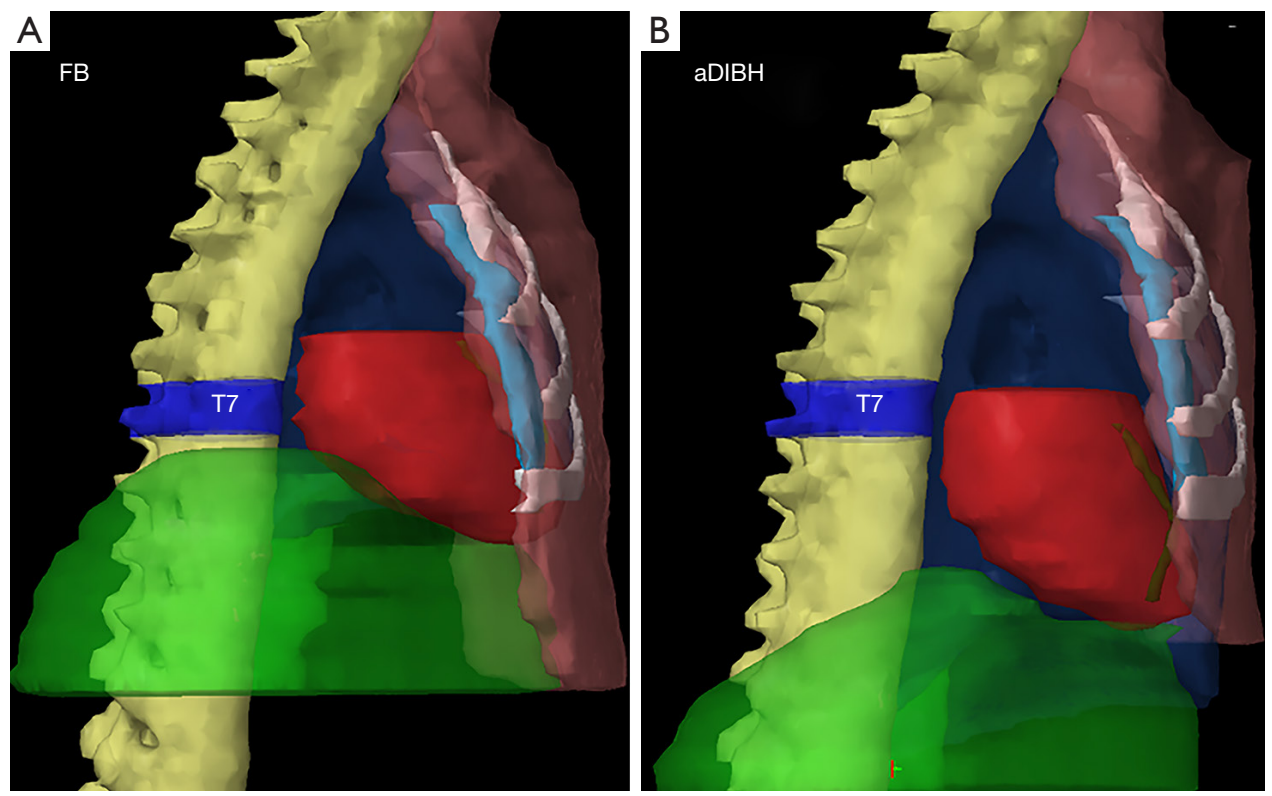

Figure 1 Spatial relationship between IMC-inclusive PTV (pink) and OARs in the tangential view. (A) Free breathing (FB); (B) abdominal deep inspiration breath-hold (aDIBH). The left lung (blue), heart (red), left anterior descending coronary artery (LAD: green), 1-4 anterior ribs (white), IMC (light blue), and the diaphragm (green) are shown as OARS. The seventh vertebral body (T7) is contoured as an internal reference. During aDIBH, the heart and LAD move caudally as compared with FB. OARs, organs at risk.

degree of downward movement of the heart and LAD was easily observed. Compared with $\mathrm{FB}$, the overlapping area was much smaller in the tangential view under aDIBH.

The heart's positional difference between $\mathrm{FB}$ and aDIBH was calculated using LDNV, which was $1.44 \pm 0.48 \mathrm{~cm}$ $(10.33 \pm 0.48$ and $8.88 \pm 1.12 \mathrm{~cm}$ during $\mathrm{aDIBH}$ and $\mathrm{FB}$, respectively) (Figure 2). Explicitly, the heart and LAD moved away from the internal mammary chain (IMC) in CT simulation during aDIBH.

\section{Heart and LAD}

As compared with $\mathrm{FB}$, all dose parameters of the heart and LAD under $\mathrm{aDIBH}$ were statistically significantly improved (Tables 2-4). With aDIBH, the $\mathrm{D}_{\text {mean }}$ of the heart and LAD were respectively reduced by $3.5 \mathrm{~Gy}(\mathrm{P}<0.003)$ and 8.9 Gy $(\mathrm{P}<0.001)$ in 3D-CRT, 2.6 Gy $(\mathrm{P}<0.001)$ and $7.8 \mathrm{~Gy}$ $(\mathrm{P}=0.001)$ in IMRT, and $1.5 \mathrm{~Gy}(\mathrm{P}<0.001)$ and $4.5 \mathrm{~Gy}$ $(\mathrm{P}=0.001)$ in VMAT plans (Figure $3 A, B)$. Among all these plans, the $\mathrm{D}_{\text {mean }}$ of the heart was lowest in $\mathrm{aDIBH}_{\text {IMRT }}$ (Figure $3 A), 1.3$ Gy lower than aDIBH ${ }_{\text {VMAT }}(\mathrm{P}=0.002)$. As compared with $\mathrm{FB}$, a reduction of $3 \mathrm{~Gy}$ in the $\mathrm{D}_{\text {mean }}$ of the heart $(\mathrm{P}=0.001)$ and $19.5 \mathrm{~Gy}$ for the $\mathrm{LAD}(\mathrm{P}<0.001)$ were observed

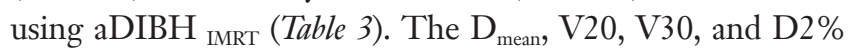

of the LAD showed a dosimetric advantage tendency with no statistical significance. Notably, the LAD's V5 was higher in the VMAT plans than with IMRT and 3D-CRT (Table 5).

\section{Lungs}

There was a significant difference in the lung volumes between FB and aDIBH, with an increase of 437.3 and $486.3 \mathrm{~mL}$ for the left and right lungs, respectively, under aDIBH (Table 2). Dosimetrically, the $\mathrm{D}_{\text {mean }}, \mathrm{V} 5, \mathrm{~V} 10, \mathrm{~V} 20$, and $\mathrm{V} 30$ of the left lung decreased in both the $\mathrm{aDIBH}_{3 \mathrm{D}-\mathrm{CRT}}$ and $\mathrm{aDIBH}$ IмRT $_{\text {IM }}$ lans compared with their counterparts of $\mathrm{FB}_{\text {3D-CRT }}$ and FB $\mathrm{IMRT}_{\text {IMT }}$ (Tables 2,3, Figure 3C). Consistently, VMAT plans resulted in higher $\mathrm{D}_{\text {mean }}, \mathrm{V} 5$, and V10 of the left lung than IMRT plans. Also, an increase of $4.2 \mathrm{~Gy}$ $(\mathrm{P}<0.001), 33.2 \%(\mathrm{P}<0.001), 11.7 \%(\mathrm{P}<0.001)$, and $0.8 \%$ $(\mathrm{P}<0.001)$ of the $\mathrm{D}_{\text {mean }}, \mathrm{V} 5, \mathrm{~V} 10$, and $\mathrm{V} 20$, respectively, were observed using aDIBH ${ }_{\text {VMAT }}$ compared with aDIBH ${ }_{\text {IMRT }}$. Overall, the respiratory mode had no effect on the right lung doses, whichever plan was applied (Table 5, Figure 3D).

\section{Contralateral breast dose analysis}

As compared with aDIBH ${ }_{\text {IMRT, }}$ aDIBH ${ }_{\text {VMAT }}$ showed 

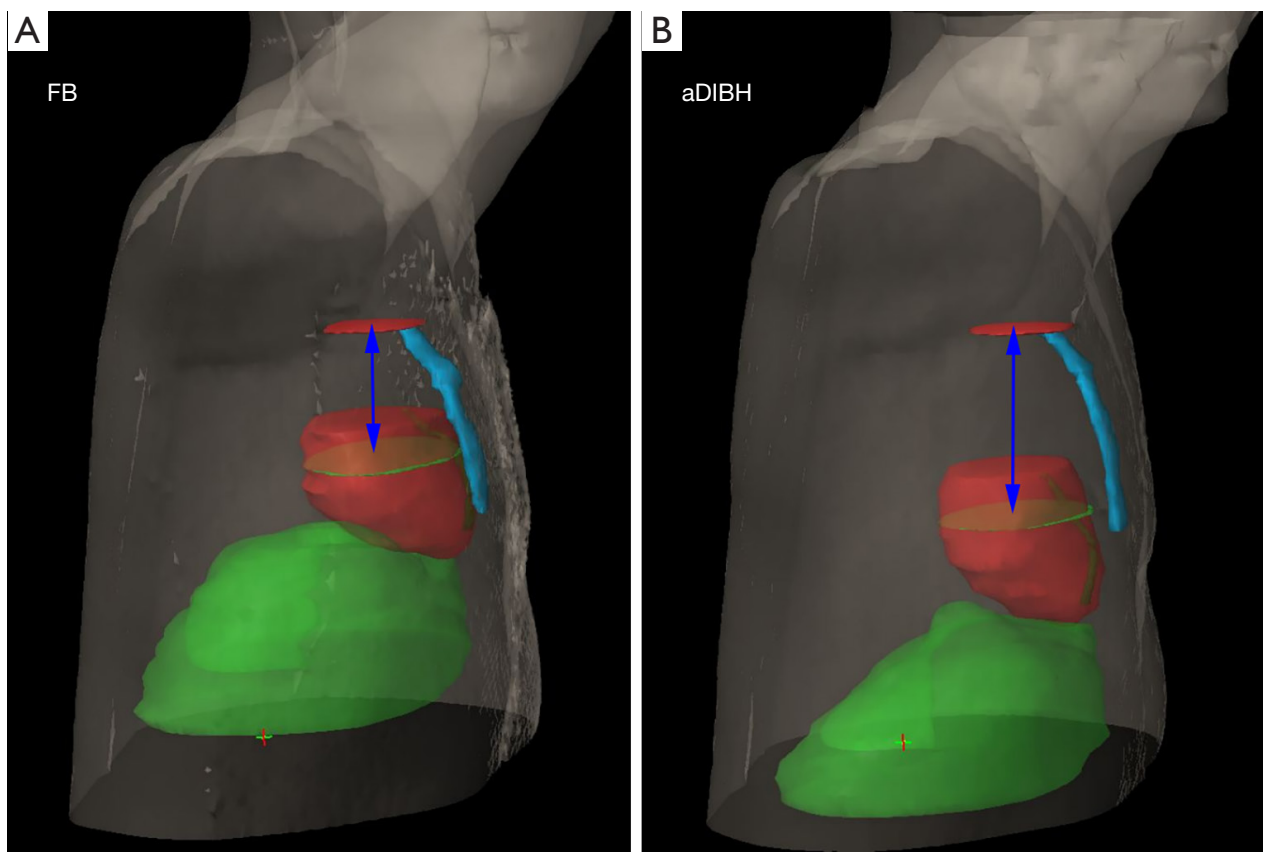

Figure 2 Double-headed arrows (dark-blue) show the longitudinal distance between the sternal notch (red) and aortic valve (green), which is significantly increased with abdominal deep inspiration breath-hold (aDIBH). Also, note the heart (red) and left anterior descending coronary artery (LAD: dark-green) move away from the internal mammary chain (IMC: light-blue) during aDIBH.

an increase of $2.4 \mathrm{~Gy}(\mathrm{P}<0.001)$ in the $\mathrm{D}_{\text {mean }}$ and $21.5 \%$ $(\mathrm{P}<0.001)$ in the V5 of the contralateral breast. Similarly, an increase of $3.5 \mathrm{~Gy}(\mathrm{P}<0.001), 27 \%(\mathrm{P}<0.001)$, and $8 \%$ $(\mathrm{P}<0.001)$ in the $\mathrm{D}_{\text {mean }}, \mathrm{V} 5$, and $\mathrm{V} 10$ were observed using $\mathrm{aDIBH}_{\text {VMAT }}$ versus aDIBH ${ }_{\text {IMRT }}$ (Table 5).

\section{PTV}

The Homogeneity Index (HI) of the PTV was $0.17 \pm 0.2$, $0.14 \pm 0.03$, and $0.13 \pm 0.01$ in $\mathrm{aDIBH}_{3 \mathrm{D}-\mathrm{CRT}}, \mathrm{aDIBH}{ }_{\text {IMRT, }}$, and $\mathrm{aDIBH}_{\text {VMAT, }}$, respectively (Tables 2,5). Among the three techniques, aDIBH ${ }_{3 \mathrm{D}-\mathrm{CRT}}$ resulted in the highest $\mathrm{HI}$, and there was no difference in $\mathrm{HI}$ between aDIBH ${ }_{\text {IMRT }}$ and aDIBH $_{\text {VMAT }}$ (Table 5).

\section{Discussion}

IMC's prophylactic irradiation has been recommended for a subset of breast cancer patients with high metastatic potential (20). However, it brings additional risk because of the considerable increase in doses to the OARs when the IMC is included in the CTV $(5,6)$. This study compared the dosimetric results obtained from six treatment plans (FB 3D-CRT $_{\text {IMRT }}, \mathrm{FB}_{\text {VMAT, }}$ aDIBH 3D-CRT, $_{\text {IMIBH }}$ IMRT, and aDIBH ${ }_{\text {VMAT }}$ ) for left-sided breast cancer patients undergoing IMC-inclusive PMRT. We found that with aDIBH, the doses to the heart and LAD were substantially decreased regardless of the treatment plan (3D-CRT, IMRT, and VMAT), which is consistent with our previous study we first proposed using aDIBH to reduce the cardiac dose further (18).

The respiratory movement executed by the intercostal muscles or the diaphragm corresponds to either thoracic or abdominal respiration. So, the deep inspiration maneuver consists of $\mathrm{tDIBH}$ and aDIBH, depending on the respective muscle groups' work. During aDIBH, the heart descends maximally together with the diaphragm, whereas the IMCinclusive PTV position stays unchanged due to suppressed sternal movement. It manifested as a difference $(1.44 \pm 0.48 \mathrm{~cm})$ in the LDNV between aDIBH and FB. As the LDNV increased, the overlapping area between the PTV and the heart in the tangential beam's eye view became much smaller in aDIBH compared with FB.

If not properly trained, the patients will perform DIBH inconsistently, resulting in varying proportions of $\mathrm{tDIBH}$ and aDIBH. Pazos et al. reported an increased amplitude of the lymph node levels' movement to be irradiated in breast cancer patients using DIBH compared with FB (21). 
Table 2 Dosimetric comparison for 3D-CRT plans based on abdominal deep inspiration breath-hold (aDIBH) and free-breathing (FB)

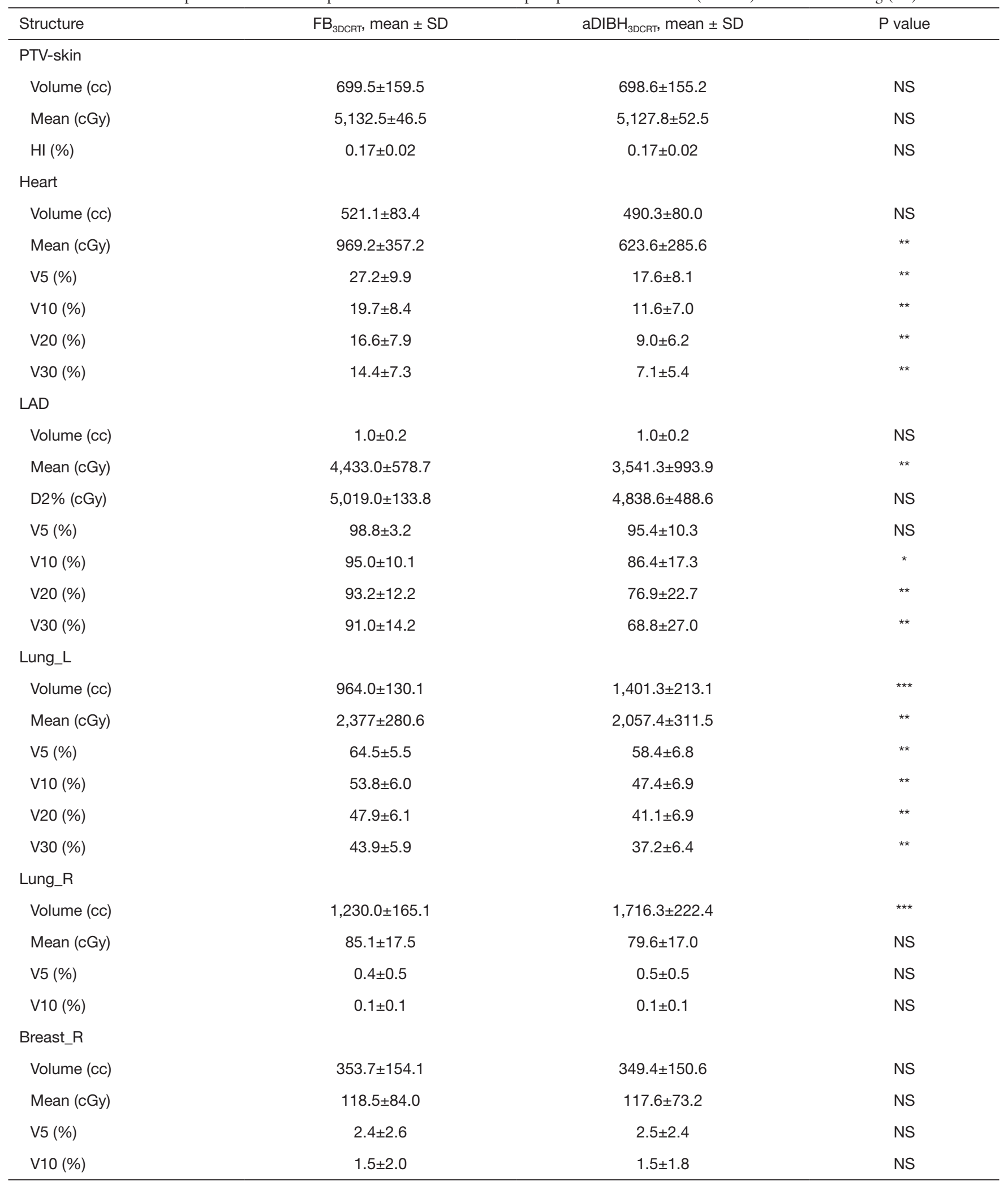

NS, no significance $(\mathrm{P}>0.05)$. Note: ${ }^{\star}, \mathrm{P}<0.05,{ }^{\star \star}, \mathrm{P}<0.01,{ }^{\star \star \star}, \mathrm{P}<0.001$. 
Table 3 Dosimetric comparison for IMRT plans based on abdominal deep inspiration breath-hold (aDIBH) and free-breathing (FB)

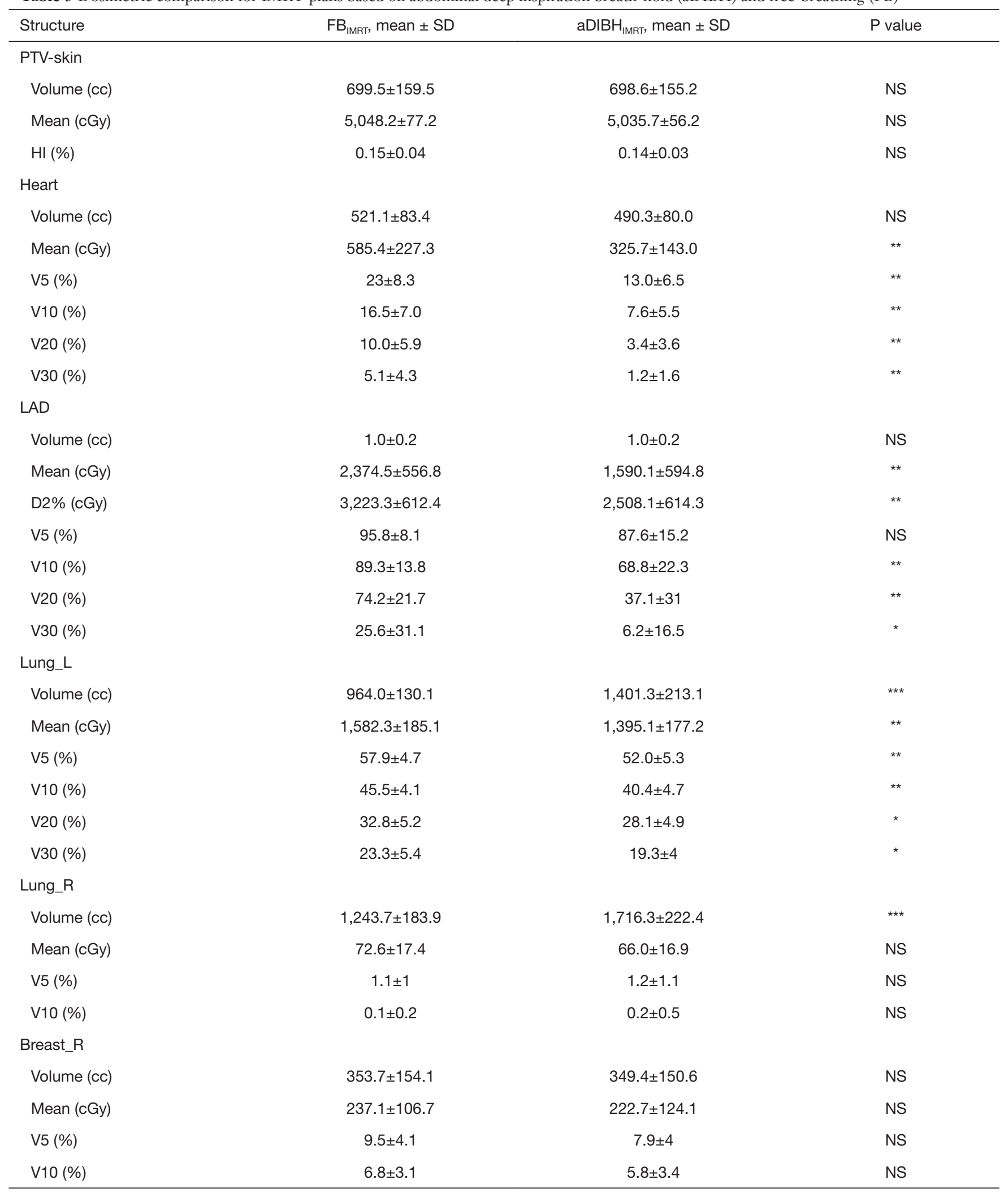

NS, no significance $(\mathrm{P}>0.05)$. Note: ${ }^{\star}, \mathrm{P}<0.05,{ }^{* \star}, \mathrm{P}<0.01$, ${ }^{* \star}, \mathrm{P}<0.001$. 
Table 4 Dosimetric comparison for VMAT plans based on abdominal deep inspiration breath-hold (aDIBH) and free-breathing (FB)

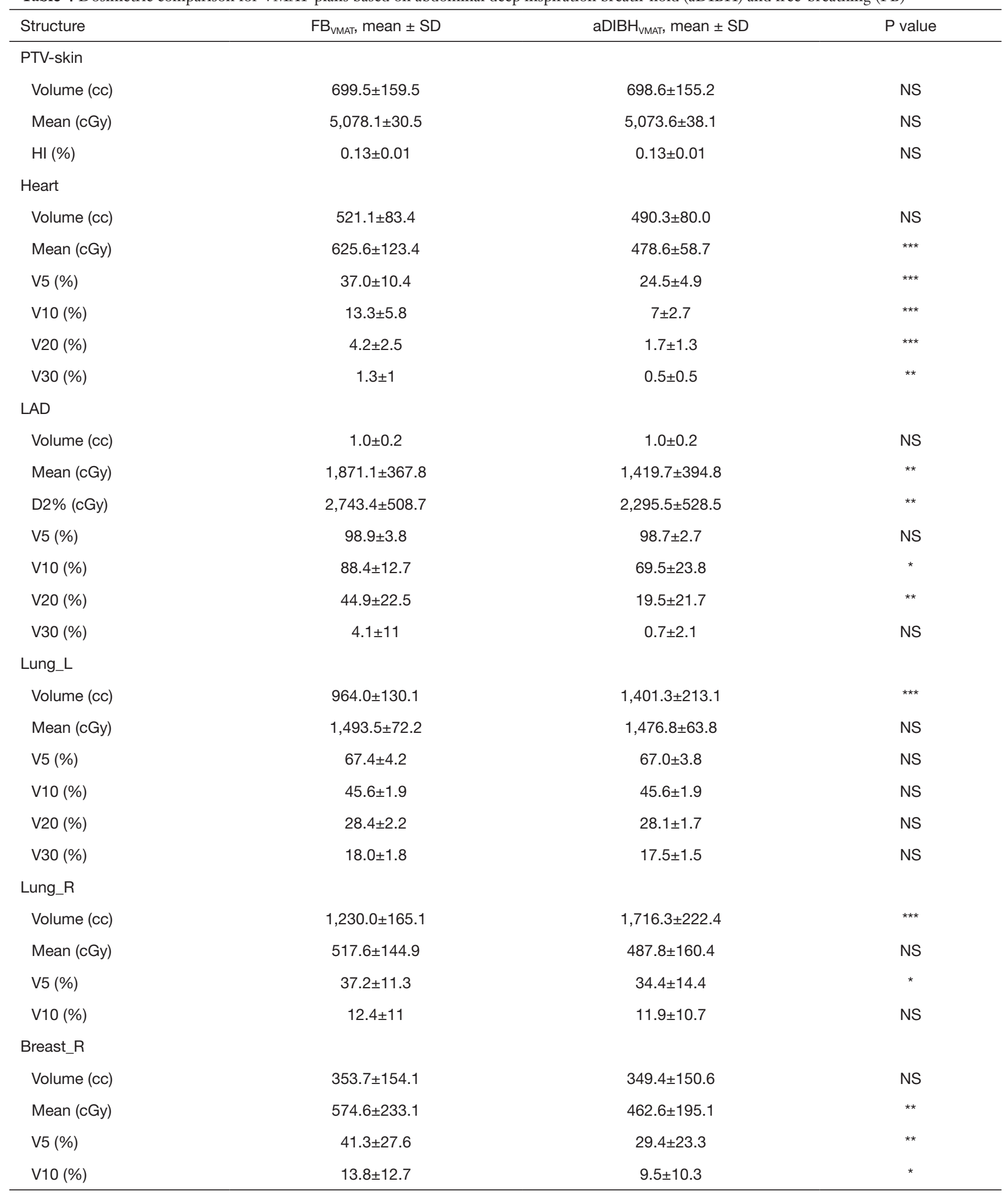

NS, no significance $(\mathrm{P}>0.05)$. Note: ${ }^{*}, \mathrm{P}<0.05,{ }^{* *}, \mathrm{P}<0.01,{ }^{* * *}, \mathrm{P}<0.001$. 

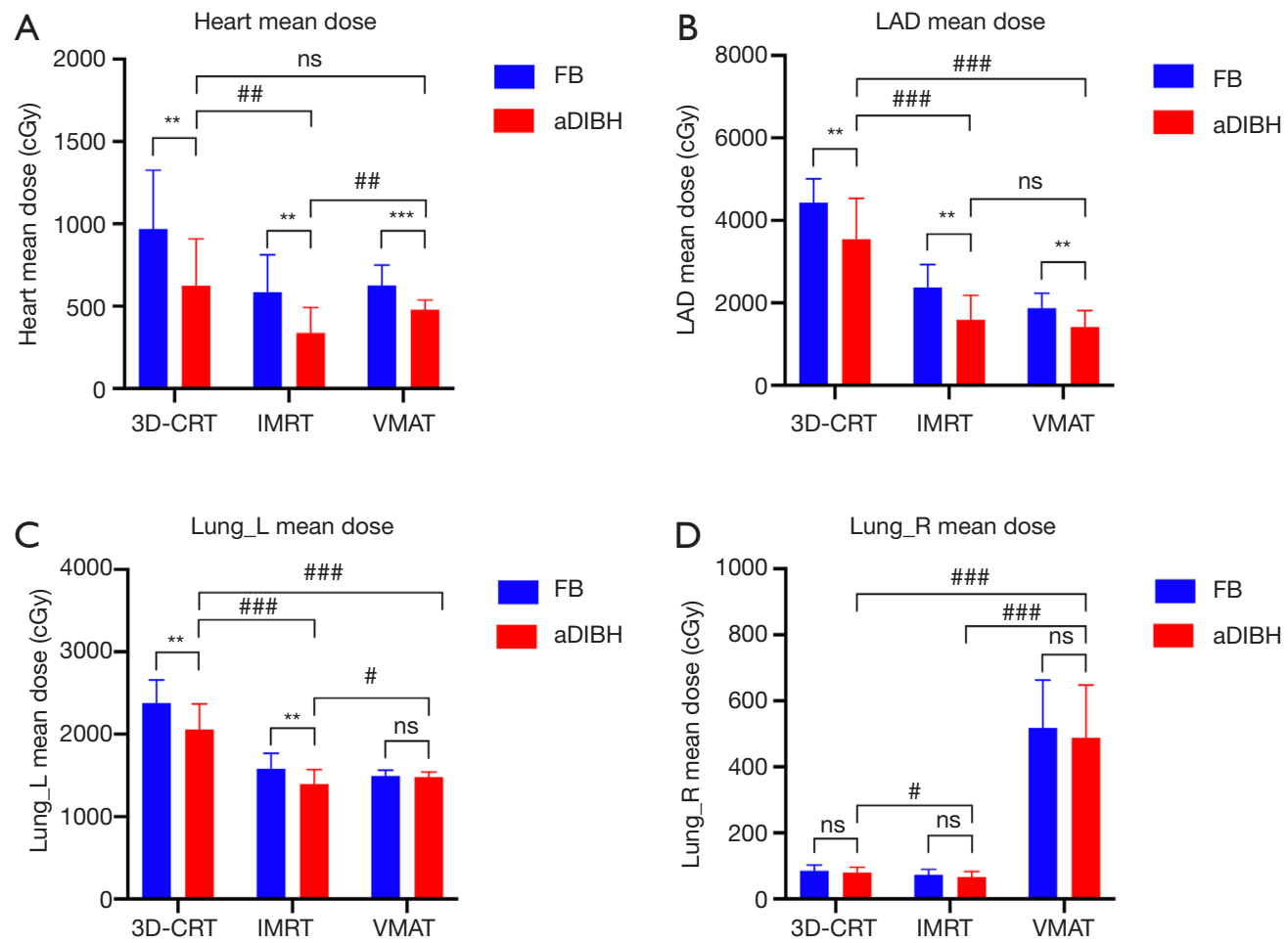

Figure 3 Mean dose of the heart (a), LAD (b), left lung (c), and right lung (d) following three-dimensional conformal radiation therapy (3D-CRT), inverse planning intensity-modulated radiation therapy (IMRT), and volumetric modulated arc therapy (VMAT), plans during FB and aDIBH. Note: P values ${ }^{*}<0.05,{ }^{* *}<0.01,{ }^{* *}<0.001 .{ }^{*}<0.05,{ }^{\# \#}<0.01,{ }^{\# \# *}<0.001$, ns: no significance. aDIBH, abdominal deep inspiration breath-hold; FB, free-breathing; LAD, left anterior descending coronary artery.

We speculate that this phenomenon derives from unstable respiration modes during DIBH and will undoubtedly increase the ITVs, which offsets the benefit of DIBH. It is overcome by prior training for the patient and auxiliary devices to restrict the sternum's anterior/superior movement that occurs with tDIBH. Our specially designed thermoplastic mesh served as an immobilization tool that both minimized the setup errors and eliminated the thoracic proportion of respiration.

As shown in Figure 4, a significant increase in lung volumes was observed during aDIBH. A positive relationship between lung expansion and cardiac sparing has been reported, and our results agree with those of previous studies (22). Besides, there was also a positive correlation between increased LDNV and cardiac dose reduction. Strikingly, in 3 of our 19 patients, the difference of LDNV between aDIBH and FB was small, resulting in insignificant cardiac sparing. Therefore, we speculate that compared with lung expansion, LDNV might better predict the advantage of aDIBH in reducing doses to the heart and LAD in patients receiving PMRT with IMC coverage. There is a need for further studies with more patient data to prove our speculation.

In this study, PTV coverage was the highest priority in multi-objective optimization in IMRT and VMAT plans. At least $95 \%$ of the PTV should be within $95 \%$ of the prescribed dose, with adequate IMC coverage in IMRT/ VMAT plans under both aDIBH and FB. In contrast, the plan quality of $3 \mathrm{D}$-CRT was relatively poor in this cohort of patients, as manifested by the higher $\mathrm{HI}(0.17)$ as compared with IMRT (0.14) and VMAT (0.13) plans. It is reported that using the field-in-field technique; HI can be significantly improved in 3D-CRT plans of the breast (23). Among all six plans, aDIBH ${ }_{\text {IMRT }}$ resulted in superior IMC dose coverage and the lowest cardiac irradiation.

PMRT can be associated with an increased risk of secondary cancers, especially of the lungs and the contralateral breast $(24,25)$. Dosimetrically, although the percentage of high-dose regions of both lungs and the right breast decreased using VMAT, the low-dose volumes 
Table 5 Dosimetric comparison for IMRT and VMAT plans based on abdominal deep inspiration breath-hold (aDIBH)

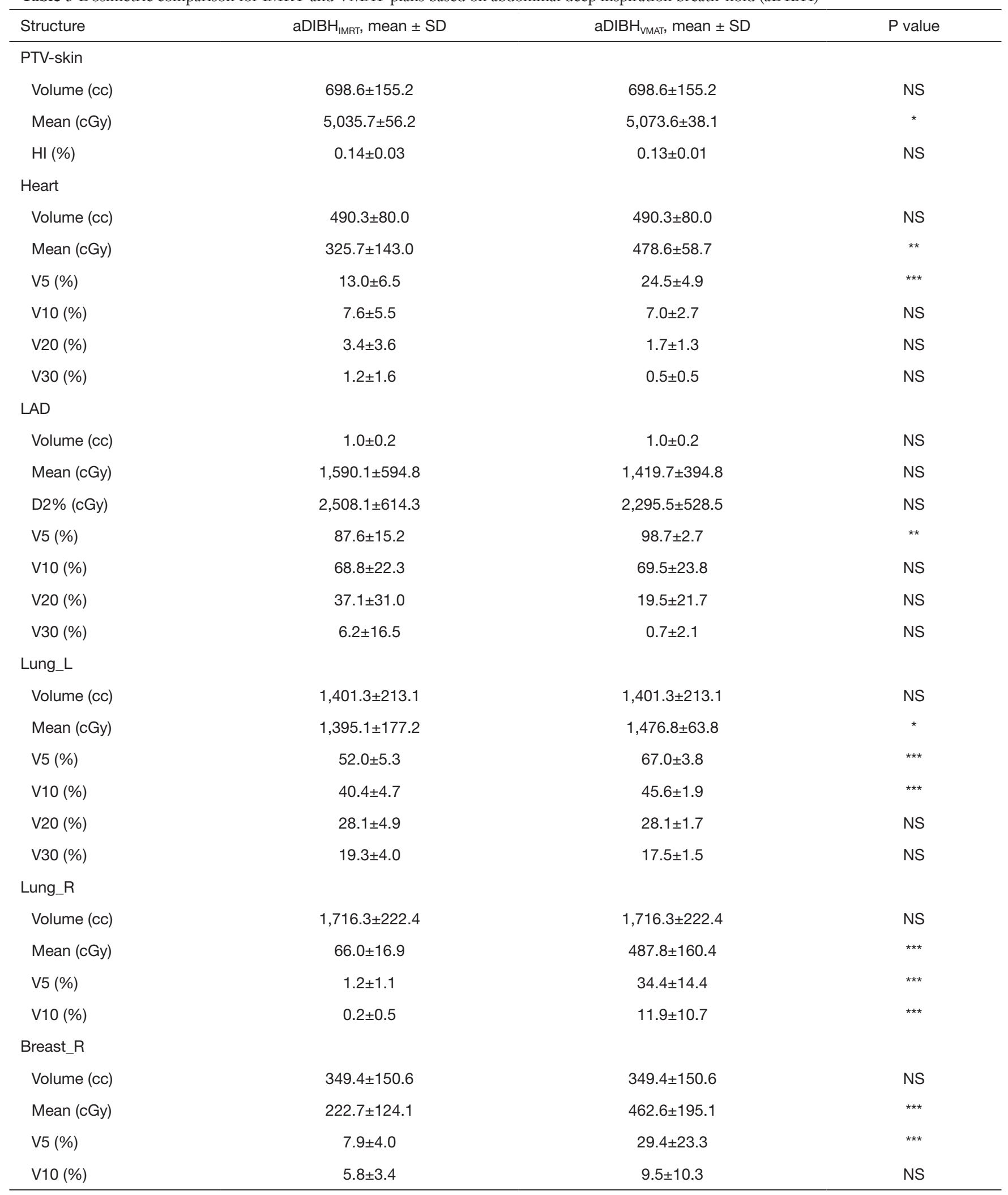

NS, no significance $(\mathrm{P}>0.05)$. Note: ${ }^{*}, \mathrm{P}<0.05,{ }^{* *}, \mathrm{P}<0.01,{ }^{* * *}, \mathrm{P}<0.001$. 

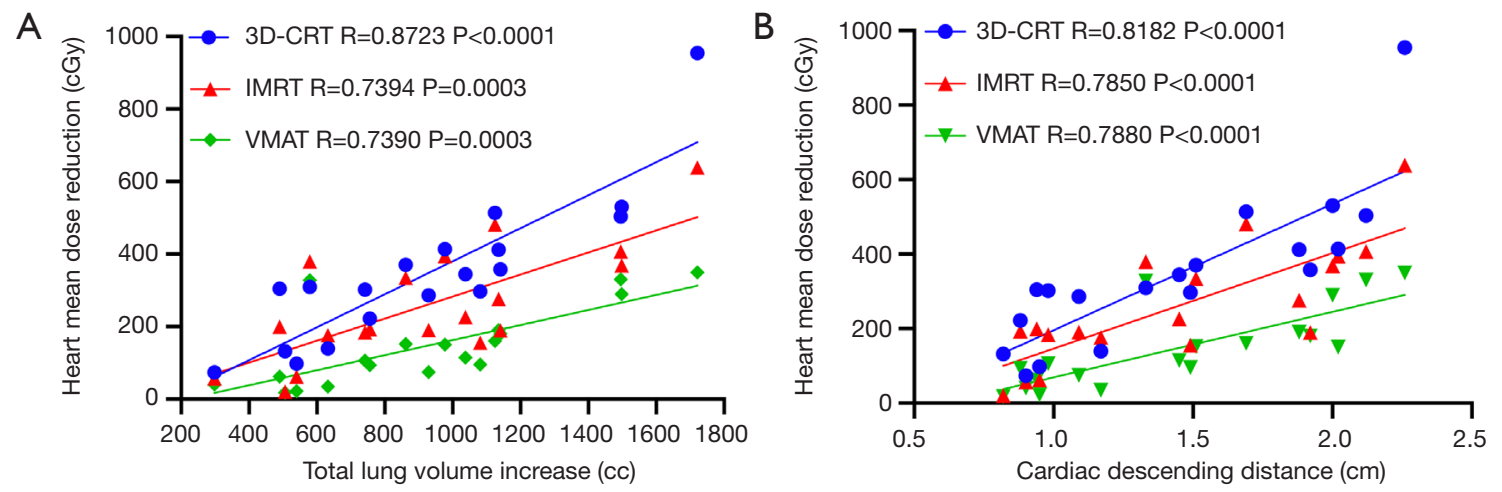

Figure 4 Correlational analyses of lung expansion and heart descent with cardiac dose. There is a positive correlation between the degree of lung expansion and cardiac dose reduction in all three treatment plans of three-dimensional conformal radiation therapy (3D-CRT), inverse planning intensity-modulated radiation therapy (IMRT), and volumetric modulated arc therapy (VMAT), most notably in 3D-CRT (A). Also, the more the heart descends, the less the radiation dose to the heart (B).

of these OARs increased considerably. This result was consistent with a report by Karpf et al. (26) and might increase the risk of developing secondary malignancies.

There are certain limitations to our study. Firstly, only 3D-CRT, inverse planning IMRT, and VMAT were utilized for dosimetric comparisons. It is reported that forwardplanning IMRT might be better in dosimetric distributions, although it is more time-consuming and prone to bias because of its need for expertise (27). Secondly, our results can not be extrapolated to all women of different ethnicities and body shapes due to the relatively small sample size. aDIBH might not apply to women with excessive abdominal obesity because of the limited diaphragmatic movement due to high intra-abdominal pressure.

\section{Conclusions}

With aDIBH, doses to the heart, LAD, and the left lung can be substantially decreased in patients receiving IMC-inclusive PMRT as compared with FB. Our specially designed immobilization device can facilitate the maneuverability and reproducibility of aDIBH. This technique has excellent clinical potential that warrants robust study with larger sample sizes.

\section{Acknowledgments}

We thank all the patients participating in the study.

Funding: This study was supported by the Zhejiang Provincial Key Discipline of Traditional Chinese Medicine
(2017-XK-A32), Chinese Medicine Research Program of Zhejiang Province (2018ZZ014), Zhejiang Provincial Natural Science Foundation \& Zhejiang Society for Mathematical Medicine (LSY19H160002), and the Health Commission of Zhejiang Province (2020KY131, 2018KY063).

\section{Footnote}

Conflicts of Interest: All authors have completed the ICMJE uniform disclosure form (available at http://dx.doi. org/10.21037/qims-20-831). The authors have no conflicts of interest to declare.

Ethical Statement: This study was approved by the hospital's Institutional Review Board and complied with the Code of Ethics of the World Medical Association (Declaration of Helsinki) for trials involving humans. Informed consent was given by all patients, who were carefully screened to rule out any contraindications to aDIBH.

Open Access Statement: This is an Open Access article distributed in accordance with the Creative Commons Attribution-NonCommercial-NoDerivs 4.0 International License (CC BY-NC-ND 4.0), which permits the noncommercial replication and distribution of the article with the strict proviso that no changes or edits are made and the original work is properly cited (including links to both the formal publication through the relevant DOI and the license). See: https://creativecommons.org/licenses/by-nc-nd/4.0/. 


\section{References}

1. Bray F, Ferlay J, Soerjomataram I, Siegel RL, Torre LA, Jemal A. Global cancer statistics 2018: GLOBOCAN estimates of incidence and mortality worldwide for 36 cancers in 185 countries. CA Cancer J Clin 2018;68:394-424.

2. Darby S, McGale P, Correa C, Taylor C, Arriagada R, Clarke M, Cutter D, Davies C, Ewertz M, Godwin J, Gray R, Pierce L, Whelan T, Wang Y, Peto R. Effect of radiotherapy after breast-conserving surgery on 10year recurrence and 15-year breast cancer death: metaanalysis of individual patient data for 10,801 women in 17 randomised trials. Lancet 2011;378:1707-16.

3. McGale P, Taylor C, Correa C, Cutter D, Duane F, Ewertz M, Gray R, Mannu G, Peto R, Whelan T, Wang Y, Wang Z, Darby S. Effect of radiotherapy after mastectomy and axillary surgery on 10-year recurrence and 20-year breast cancer mortality: meta-analysis of individual patient data for 8135 women in 22 randomised trials. Lancet 2014;383:2127-35.

4. Nguyen MH, Lavilla M, Kim JN, Fang LC. Cardiac sparing characteristics of internal mammary chain radiotherapy using deep inspiration breath hold for leftsided breast cancer. Radiat Oncol 2018;13:103.

5. Taylor CW, Wang Z, Macaulay E, Jagsi R, Duane F, Darby SC. Exposure of the Heart in Breast Cancer Radiation Therapy: A Systematic Review of Heart Doses Published During 2003 to 2013. Int J Radiat Oncol Biol Phys 2015;93:845-53.

6. Aznar MC, Duane FK, Darby SC, Wang Z, Taylor CW. Exposure of the lungs in breast cancer radiotherapy: A systematic review of lung doses published 2010-2015. Radiother Oncol 2018;126:148-54.

7. Paszat LF, Mackillop WJ, Groome PA, Schulze K, Holowaty E. Mortality from myocardial infarction following postlumpectomy radiotherapy for breast cancer: a population-based study in Ontario, Canada. Int J Radiat Oncol Biol Phys 1999;43:755-62.

8. Darby SC, Ewertz M, McGale P, Bennet AM, BlomGoldman U, Bronnum D, Correa C, Cutter D, Gagliardi G, Gigante B, Jensen MB, Nisbet A, Peto R, Rahimi $\mathrm{K}$, Taylor C, Hall P. Risk of ischemic heart disease in women after radiotherapy for breast cancer. N Engl J Med 2013;368:987-98.

9. Giordano SH, Kuo YF, Freeman JL, Buchholz TA, Hortobagyi GN, Goodwin JS. Risk of cardiac death after adjuvant radiotherapy for breast cancer. J Natl Cancer Inst 2005;97:419-24.
10. Corradini S, Ballhausen H, Weingandt H, Freislederer P, Schönecker S, Niyazi M, Simonetto C, Eidemüller M, Ganswindt U, Belka C. Left-sided breast cancer and risks of secondary lung cancer and ischemic heart disease : Effects of modern radiotherapy techniques. Strahlenther Onkol 2018;194:196-205.

11. Gaasch A, Schönecker S, Simonetto C, Eidemüller M, Pazos M, Reitz D, Rottler M, Freislederer P, Braun M, Würstlein R, Harbeck N, Niyazi M, Belka C, Corradini $\mathrm{S}$. Heart sparing radiotherapy in breast cancer: the importance of baseline cardiac risks. Radiat Oncol 2020;15:117.

12. Sardaro A, Petruzzelli MF, D'Errico MP, Grimaldi L, Pili G, Portaluri M. Radiation-induced cardiac damage in early left breast cancer patients: risk factors, biological mechanisms, radiobiology, and dosimetric constraints. Radiother Oncol 2012;103:133-42.

13. Shapiro CL, Hardenbergh PH, Gelman R, Blanks D, Hauptman P, Recht A, Hayes DF, Harris J, Henderson IC. Cardiac effects of adjuvant doxorubicin and radiation therapy in breast cancer patients. J Clin Oncol 1998;16:3493-501.

14. Smyth LM, Knight KA, Aarons YK, Wasiak J. The cardiac dose-sparing benefits of deep inspiration breath-hold in left breast irradiation: a systematic review. J Med Radiat Sci 2015;62:66-73.

15. Jagsi R, Griffith KA, Moran JM, Ficaro E, Marsh R, Dess RT, Chung E, Liss AL, Hayman JA, Mayo CS, Flaherty K, Corbett J, Pierce L. A Randomized Comparison of Radiation Therapy Techniques in the Management of Node-Positive Breast Cancer: Primary Outcomes Analysis. Int J Radiat Oncol Biol Phys 2018;101:1149-58.

16. Sixel KE, Aznar MC, Ung YC. Deep inspiration breath hold to reduce irradiated heart volume in breast cancer patients. Int J Radiat Oncol Biol Phys 2001;49:199-204.

17. Borm KJ, Oechsner M, Combs SE, Duma MN. DeepInspiration Breath-Hold Radiation Therapy in Breast Cancer: A Word of Caution on the Dose to the Axillary Lymph Node Levels. Int J Radiat Oncol Biol Phys 2018;100:263-9.

18. Zhao F, Shen J, Lu Z, Luo Y, Yao G, Bu L, Ge J, Yang $X$, Ning L, Yan S. Abdominal DIBH reduces the cardiac dose even further: a prospective analysis. Radiat Oncol 2018;13:116.

19. White J, Tai A, Arthur D, Buchholz T, MacDonald S, Marks L, Pierce L, Recht A, Rabinovitch R, Taghian R, Vicini R, Woodward W, Li XA. Breast cancer atlas for radiation therapy planning: Consensus definitions. 
Available online: https://www.nrgoncology.org/Portals/0/ Scientific\%20Program/CIRO/Atlases/BreastCancerAtlas_ corr.pdf?ver=2018-04-18-144201-270. Accessed April 18, 2018.

20. Duane FK, McGale P, Teoh S, Mortimer C, Broggio J, Darby SC, Dodwell D, Lavery B, Oliveros S, Vallis KA, Taylor CW. International Variation in Criteria for Internal Mammary Chain Radiotherapy. Clin Oncol (R Coll Radiol) 2019;31:453-61.

21. Pazos M, Fiorentino A, Gaasch A, Schonecker S, Reitz D, Heinz C, Niyazi M, Duma MN, Alongi F, Belka C, Corradini S. Dose variability in different lymph node levels during locoregional breast cancer irradiation: the impact of deep-inspiration breath hold. Strahlenther Onkol 2019;195:13-20.

22. Oechsner M, Düsberg M, Borm KJ, Combs SE, Wilkens JJ, Duma MN. Deep inspiration breath-hold for left-sided breast irradiation: Analysis of dose-mass histograms and the impact of lung expansion. Radiat Oncol 2019;14:109.

23. Ohashi T, Takeda A, Shigematsu N, Fukada J, Sanuki N, Amemiya A, Kubo A. Dose distribution analysis of axillary lymph nodes for three-dimensional conformal radiotherapy with a field-in-field technique for breast cancer. Int J Radiat Oncol Biol Phys 2009;73:80-7.

24. Grantzau T, Overgaard J. Risk of second non-breast cancer among patients treated with and without postoperative radiotherapy for primary breast cancer: A systematic review and meta-analysis of population-based studies including 522,739 patients. Radiother Oncol 2016;121:402-13.

25. Stovall M, Smith SA, Langholz BM, Boice JD Jr, Shore RE, Andersson M, Buchholz TA, Capanu M, Bernstein L, Lynch CF, Malone KE, Anton-Culver H, Haile RW, Rosenstein BS, Reiner AS, Thomas DC, Bernstein JL; Women's Environmental, Cancer, and Radiation Epidemiology Study Collaborative Group. Dose to the contralateral breast from radiotherapy and risk of second primary breast cancer in the WECARE study. Int J Radiat Oncol Biol Phys 2008;72:1021-30.

26. Karpf D, Sakka M, Metzger M, Grabenbauer GG. Left breast irradiation with tangential intensity modulated radiotherapy (t-IMRT) versus tangential volumetric modulated arc therapy (t-VMAT): trade-offs between secondary cancer induction risk and optimal target coverage. Radiat Oncol 2019;14:156.

27. Donovan EM, Ciurlionis L, Fairfoul J, James H, Mayles H, Manktelow S, Raj S, Tsang Y, Tywman N, Yarnold J, Coles C. Planning with intensity-modulated radiotherapy and tomotherapy to modulate dose across breast to reflect recurrence risk (IMPORT High trial). Int J Radiat Oncol Biol Phys 2011;79:1064-72.
Cite this article as: Chen $M, Z$ ang $S, Y u H$, Ning L, Huang H, Bu L, Ge J, Xu M, Tang Q, Zhao F, Yao G, Yan S. Immobilization-assisted abdominal deep inspiration breathhold in post-mastectomy radiotherapy of left-sided breast cancer with internal mammary chain coverage. Quant Imaging Med Surg 2021;11(7):3314-3326. doi: 10.21037/qims-20-831 


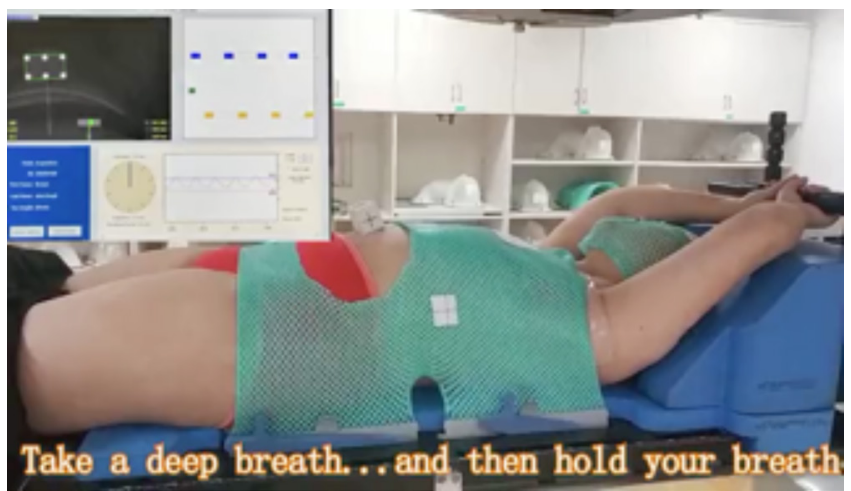

Figure S1 The picture of abdominal DIBH setup. 